\title{
Revealing the Shopper Experience of Using a 'Magic Mirror' Augmented Reality Make-Up Application
}

\author{
Ana Javornik \\ Università della Svizzera \\ italiana \\ Lugano \\ Switzerland \\ ana.javornik@usi.ch
}

\author{
Yvonne Rogers \\ University College \\ London \\ WC1E 6EA \\ London, UK \\ y.rogers@ucl.ac.uk
}

\author{
Ana Maria Moutinho \\ University College \\ London \\ WC1E 6BT \\ London, UK \\ ana.moutinho.11@ucl.ac.uk
}

\author{
Russell Freeman \\ Holition Ltd \\ EC1N 2PL \\ London, UK \\ russell.freeman@ \\ holition.com
}

\begin{abstract}
Virtual try-ons have recently emerged as a new form of Augmented Reality application. Using motion caption techniques, such apps show virtual elements like make-up or accessories superimposed over the real image of a person as if they were actually wearing them. However, there is as of yet little understanding about their value for providing a viable experience. We report on an in-situ study, observing how shoppers approach and respond to such a "Magic Mirror" in a store. Our findings show that after the initial surprise, the virtual try-on resulted in much exploration when shoppers looked at themselves on a display integrated in the make-up counter. Behavior tracking data from interactions with the mirror supported this. Moreover, survey data measured perceptions of augmentation as well as hedonic and utilitarian value of the app and suggested the augmented experience was perceived to be playful and credible while also acting as a strong driver for future behavior. We discuss opportunities and challenges that such technology brings for shopping and other domains.
\end{abstract}

\section{Author Keywords}

Augmented reality; virtual try-on; in-the-wild study; shopper experience; make-up.

\section{ACM Classification Keywords}

H.5.m. Information interfaces and presentation (e.g., HCI): Miscellaneous.

\section{INTRODUCTION}

Augmented Reality (AR) has become increasingly available for end-consumers, mainly through smart device applications, but also through public interactive displays. Examples include apps for navigation, viewing property prices and tourist guides. Contextualized information (e.g. a

\footnotetext{
Permission to make digital or hard copies of all or part of this work for personal or classroom use is granted without fee provided that copies are not made or distributed for profit or commercial advantage and that copies bear this notice and the full citation on the first page.

Copyrights for components of this work owned by others than ACM must be honored. Abstracting with credit is permitted. To copy otherwise, or republish, to post on servers or to redistribute to lists, requires prior specific permission and/or a fee.

Request permissions from Permissions@acm.org.

DIS 2016, June 04-08, 2016, Brisbane, QLD, Australia (C) 2016 ACM. ISBN 978-1-4503-4031-1/16/06 ..\$15.00

DOI: http://dx.doi.org/10.1145/2901790.2901881
}

restaurant, a direction arrow, a figure in $\$ \$ \$$ ) is typically overlaid on a view of the real world shown on a device display and captured by its internal camera as the user moves through a street or city.

A new kind of AR technology that is starting to be used as part of smart device applications is the "Magic Mirror". The image of a person's face, which appears on a device screen via the in-built camera (typically used for videoconferencing), is superimposed with add-ons such as make-up or accessories (see Figure 1). In contrast to other AR apps that overlay the rear-facing camera image of the surroundings with digital information [3], the Magic Mirror uses the front-facing camera. In so doing, it delivers a different user experience as it seeks to make the virtual appear as part of the real, rather than being superimposed over it. One kind of app using this technology is a virtual make-up try-on where the add-ons are created to realistically enhance the face; as far as possible giving the impression that one is truly trying on the make-up. When the user moves their head, so too does the make-up by staying in the same place on the mirrored face. This illusion works through the application of motion capture techniques that build up an internal 2D model of a person's facial features in real time. The effect is quite magical, as the virtual make-up appears very realistic. However, it is not yet known whether this technique is effective in terms of 'fooling' users into thinking it is genuine and whether they would use it when selecting make-up in a retail store. A question this raises is how convincing is the app to shoppers and does it entice them to try more or different kinds of make-up than they would otherwise?

Our research is concerned with investigating the uptake of this novel kind of AR technology in a real-world context. Specifically we ask: how does Magic Mirror as a new kind of AR application affect the shopping experience when in a public retail space?

We report here on an in-situ study which investigated how shoppers approached a make-up counter in a real store which had embedded the Magic Mirror AR technology as part of its display. The study was set up in a futuristic store in a large shopping center. A mixed method approach was used: in-situ observation and an extensive survey. Our 


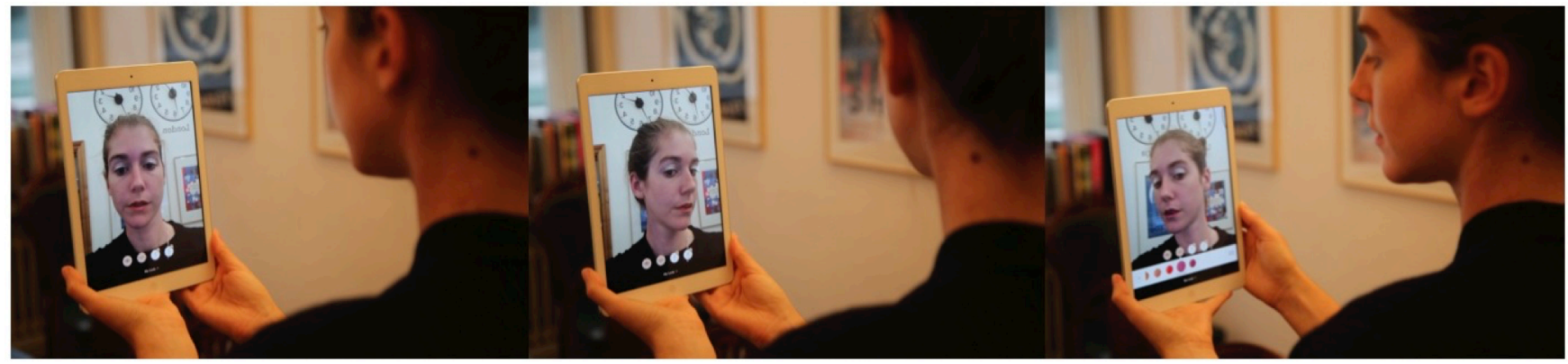

Figure 1: Captures of a face from different angles, showing the application's tracking and the make-up following the users' moves

findings showed that people did not simply walk up and use it but had to be talked through how to use it by an assistant or watch someone else before having a go. Those who did try it were initially surprised by the effect but then took it seriously and went on to experiment with a variety of features. We discuss how the success of these new kinds of AR technologies in a store depends on a range of factors, including whether the application is noticed, whether people feel comfortable trying it on, how long they use it for and what they do after using it. Finally, we examine the value of the Magic Mirror in a retail setting, in terms of its potential for enhancing the shopper experience versus the risk of it being perceived more as a playful gimmick. While this application was designed for a specific context, it is likely to have wider applications for other fields such as medicine, culture and education if shown that people react positively to the virtual face augmentation.

\section{BACKGROUND}

Previous research on AR has predominantly focused on the technical challenges when using AR technology to superimpose the surroundings with virtual annotations $[2,6,19,32]$. Issues such as how to improve tracking and rendering $[19,32]$ or how to integrate $A R$ when using wearables [6] have been dominating the research agenda. These include investigating the complete visual hardware pipeline from image capture and processing through to rendering and display. The technological advances of the last decade have seen all of these components coming together in integrated mobile devices [20]. Ever smaller processors with greater processing capabilities, increased storage capacity, ubiquity of wireless Internet, mass adoption of smartphones and tablets and effectively unlimited storage capacity of on-line information have all contributed to the opening up of AR development and its commercial possibilities. There are now software development kits (SDKs) available commercially that enable assembly of components within AR applications, such as $A R$ recognition, tracking and content rendering (Vuforia, wikitude, D'fusion, ARToolKit or ARmedia) [1]. Although these SDKs allow many companies to rapidly create novel AR apps, customized development of tracking and visualization components are often still required.
The areas where AR has seen most advances are tourism [18,30], aviation [10], culture [29] and education [8,11,30]. Further opportunities exist in learning more about how AR affects the user experience in real world contexts, in terms of whether, and the extent to which, the additional information enhances the experience, how immersive it feels or whether it deepens understanding or learning [27]. A question for all of these domains is how does the AR technology change the user experience? Does superimposing virtual information on a view of the real world on a display help people make decisions or enable them to understand better the context in real time? Is the way the information appears on the screen realistic enough and perceived as useful - in the way heads up display AR is commonly used in cockpits to help land planes?

The research investigating the user experience of AR has been emerging only recently $[7,8,13,26]$. A study by Kourouthanassis et al. [18] investigated the role of emotions in the adoption behavior of mobile AR systems for personalized tourist recommendations. They found that affect and arousal, as evoked by a system's functional features, strongly impacted the user's willingness to use it. In the context of education, Chang et al. [7] have shown that an AR application that augments an art object with additional information can increase knowledge retention and deepens appreciation of paintings.

AR has begun to receive attention in marketing [26]. There is much interest in its potential for delivering an amended consumer experience, by which we refer to user experience that relates to consumption activities, both in public (such as retail) or private contexts (such as online shopping). One of the first commercial applications was designed in 2008 for the car brand Mini, which presented a simulation of the car on a screen when a paper with corresponding trackers was placed in front of it [6]. The car appeared in 3D and moved when a user tilted the piece of paper it appeared on. That enabled the user to view a $3 \mathrm{D}$ visualization of the car model in any perspectives he defined with his moves, therefore not needing to click on the mouse to rotate the model. Since then, other simulations of products in a physical space have started appearing. Furniture brands, like Ikea, can now mimic pieces of furniture on a smart 
device screen as if it was literally placed in someone's living room. This is intended to help customers imagine how a three-piece suite or dining table would appear in their living room by superimposing the virtual furniture in an image of it. Huang and Liu [13] have shown that when AR simulates products such as furniture in a surrounding space, it creates a strong experiential value, especially when integrated in the consumer journey.

Uses of AR in marketing have diversified in several directions [15]. Companies such as Aurasma or LogoGrab have developed applications that augment products with $3 \mathrm{D}$ pop-ups and other visual content that appear when using AR tracking on a smartphone. Other examples of AR in commercial settings include enriching surroundings with interactive displays or mirrors in a store. An example is an interactive wall display in a shop which shows snowflakes and gifts appearing as the shopper walks past it. However, very few user studies have been conducted to examine the efficacy and impact of AR technologies in this context [26].

Another kind of AR app that has appeared for commercial purpose is the virtual try-on. Early types of virtual try-on technology comprised either a) avatar-based simulations where products are not tried on in real time on the users themselves but rather on a virtual proxy that resembles the user's features and that the user can then manipulate [14,17] or b) photo-based try-ons where products are tried on a user's photo, which provides a static $2 \mathrm{D}$ experience $[9,21]$. The effect that both create is to show someone how they would appear with the product (make-up, glasses, apparel) on by placing the particular item on the uploaded user photo or on a customized avatar. Studies of such virtual try-ons using virtual jewelry, make-up and clothes found that both hedonic and utilitarian aspects play an important role in the user experience [9,23]. However, in some cases the entertainment value can be a stronger cause for adoption of product virtualization technologies than usefulness, i.e. the more functional value [17]. Personal characteristics of users, such as their openness towards novelty (typical for early adopters) [14] and body image [23], are important determinants of such try-ons' perceived value. The users that are more curious about innovative technology (typically early adopters) would, for instance, pay more attention towards functional features and the application's quality, while those with lower level of so-called cognitive innovativeness would be more likely to use it again if it was easy to use and playful [14]. While one study has examined how users react to make-up being placed on a photo of them [22], there hasn't been any evaluation so far investigating how people react to using the Magic Mirror with its accurate real-time tracking, which differs from previous virtual try-on forms.

Here, we are interested in how people take to the Magic Mirror kind of AR, and more particularly, what they make of such an illusion. The goal of our research is to understand how it impacts the shopping experience, especially their initial perception, their willingness to experiment with products and the effect the experience of trying on different virtual make-up brands has on them. Building on previous work, we aim to investigate to which extent the levels of playfulness and convenience act as drivers for behavior when shoppers view the augmentation features to be credible. Most of the previous research related to virtual try-ons has been conducted in controlled settings. Here, we investigate the use of the application in the wild in order to offer insights from a real-life context.

\section{RESEARCH AIMS AND OBJECTIVES}

The aim of our research is to understand better the interplay between the new type of Magic Mirror AR technology in the retail context and reactions of shoppers towards it. In particular, we were concerned with addressing how such an experience fits into the consumer journey and shopping process. We were also interested in discovering whether there were any unexpected effects or modalities of use. For this purpose, we investigated the types of responses that a tablet with the Magic Mirror AR elicited when situated at a make-up stand in a store and examined the forms of interaction that emerge between shoppers, shop assistants and this type of AR technology.

\section{THE MAGIC MIRROR MAKE-UP APP}

The Magic Mirror app, developed for a well-known cosmetics brand by a company specializing in AR technology, allows users to try on virtual make-up. It enables the user to try make-up from the following product categories: lipstick and glosses, foundation, eye shadow and blush. In addition to this, the app has a feature allowing predefined combinations to be tried where multiple products are assembled into complete looks. All of the products available in the make-up app are real products offered for testing or purchase in the brand's store.
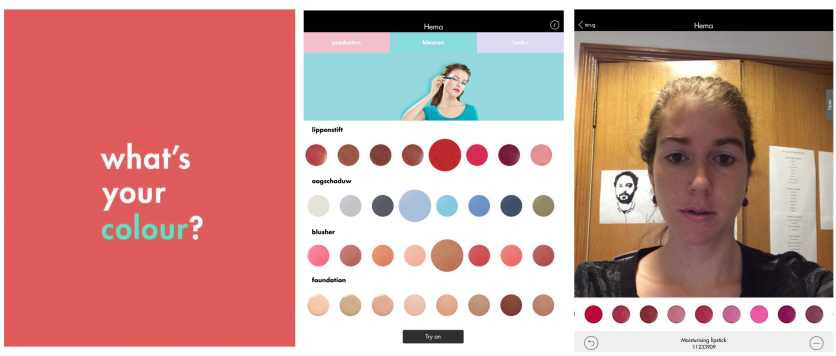

Figure 2: Screen shots of the app's content: screen saver (left), menu for choosing colors (middle) and virtual try-on mode (right)

To attract the attention of shoppers, a screensaver displayed the make-up brand logo and the question 'What's your colour?" The rationale was that it would draw passers-by to the app, encourage them to start using it and try out the different colors of make-up. When the screen is touched, the main menu appears and the user can choose either the color menu or the product menu (Figure 2). Upon choosing a color or product, the virtual try-on mode is displayed, where the shopper can see his own face in the camera 
mirror with the addition of the selected make-up. When in the try-on mode, the shopper can change the colors of the product by flipping through circles with specific color tones on the bottom of the screen. When a color is tapped on, it appears on the person's mirrored face. The application is intended for individual use and cannot simultaneously track more than one face.

\section{SETTING}

The Magic Mirror technology was placed in a large store located in a shopping mall in the center of a large European city. The store has been set up to provide a futuristic style of retailing where different areas present innovative products or interactive technologies intended to offer new kinds of consumer retail experience. Such a setting represents an opportunity to learn about innovation in retail, while at the same time enabling shoppers to browse and buy a variety of goods from the store.

In the store, the brand's retail area displays various product lines together with testers as in a typical beauty or cosmetics department. The Magic Mirror application was installed on two tablets that were placed at eye level in the make-up counter so as to be integrated with the process of product browsing.

\section{METHODOLOGY}

A user study was carried out alongside a larger evaluation of the make-up app that the cosmetics brand, the AR company and the store were conducting. We were invited to study the shopping experience by visiting the store after the make-up app had been set up. Hence our involvement was one of an independent research group that was to investigate the app being used in-situ. As such, we were free to come up with our own methodology but not able to shape the way the app was configured in the store.

We used a mixed methods approach where both quantitative and qualitative data were collected: initially we directly observed consumer behavior with the app in-situ for a week and afterwards collected visitors' comments about their experience. We also collected data about the interactions with the system. Moreover, during a period of three months, shoppers that had used the application were invited by the shop assistants to participate in a survey.

\section{In-the-wild study}

The observational study was conducted throughout the week during the nine-hour opening time. One of the researchers was present in the store where the make-up apps were running on two tablets. She observed approximately 120 people interacting with them. Each day there were between 30 to 40 people visiting the whole store, but not all of them came to the cosmetics counter or interacted with the app.

The researcher observed the visitors and made notes when they interacted with the application on their own or with others. Particular attention was paid to: a) how visitors approached and interacted with the make-up app, b) the most frequently used app features, c) visitors' comments and their bodily responses when trying out the app and d) the follow-up behavior.

\section{Survey}

Data was collected from 105 shoppers, first by the researcher during the observational study and then by the shop assistants for the remaining 3 months of the trial (who, after the researcher left, then themselves started inviting people to take part in the survey after using the app). 3 responses were eliminated as invalid, so the final sample consisted of 102 responses. In agreement with the store, the survey appeared through a link on the display after a shopper had used the app.

Statements in the survey measuring different levels of consumer experience

\begin{tabular}{|c|c|}
\hline $\begin{array}{l}\text { Perceived } \\
\text { augmentation } \\
\text { Adopted from } \\
\text { Javornik [16] }\end{array}$ & $\begin{array}{l}\text { a) The application added virtual make up } \\
\text { to my face; } \\
\text { b) The way the make up was placed on } \\
\text { my face seemed real; } \\
\text { c) The make up seemed to be part of my } \\
\text { face; } \\
\text { d) The make-up moved together with my } \\
\text { face when I turned my head; } \\
\text { e) The make up seemed to exist in real } \\
\text { time. }\end{array}$ \\
\hline $\begin{array}{l}\text { Playfulness } \\
\text { Adopted from } \\
\text { Moon and } \\
\text { Kim [24] }\end{array}$ & $\begin{array}{l}\text { Using the application } \\
\text { a) was enjoyable for me; } \\
\text { b) was fun for me; } \\
\text { c) made me happy; } \\
\text { d) made me curious; } \\
\text { e) made me more creative; } \\
\text { d) led me to exploration. }\end{array}$ \\
\hline $\begin{array}{l}\text { Convenience } \\
\text { Adopted from } \\
\text { Forsythe et al. } \\
{[12]}\end{array}$ & $\begin{array}{l}\text { The application enabled me to } \\
\text { a) virtually try on more products than I } \\
\text { usually do; } \\
\text { b) feel less pressure to buy the products I } \\
\text { tried than if I had tried the real ones; } \\
\text { c) search for product information on the } \\
\text { application while trying the products. }\end{array}$ \\
\hline $\begin{array}{l}\text { Behavioral } \\
\text { intentions } \\
\text { Adopted from } \\
\text { van Noort et } \\
\text { al. [25] }\end{array}$ & $\begin{array}{l}\text { I have the intention to } \\
\text { a) return to this application in the future; } \\
\text { b) talk to my friends and colleagues about } \\
\text { it; } \\
\text { c) buy one or more of the products I've } \\
\text { tried. }\end{array}$ \\
\hline
\end{tabular}

Table 1: List of statements included in the survey

To provide an incentive for completing the survey, users were offered a $15 \%$ discount for subsequent purchases. It took between 1-3 minutes for a participant to answer the questions. The survey asked questions about how the shoppers perceived the AR application when they tried it, the nature of their shopping journey and their future behavior intentions related to the application. 
A 7-point Likert scaled was used for each statement, with 7 representing complete agreement with the statement and 1 complete disagreement. The sets of statements addressed: a) consumer perception of AR features, i.e. augmentation; b) playfulness; c) convenience and d) behavioral intentions (see Table 1). The initial objective of the survey was to obtain opinions from Magic Mirror users over a longer period of time than would have been possible to observe the behavior in the store. Secondly, we also aimed to analyze to which extent the perception of such augmentation coincides with the playfulness of the experience and, furthermore, if that leads to behavioral intentions. For this purpose we ran descriptive analysis as well as regression analysis, with the latter allowing us to evaluate the prediction power of different dimensions related to this shopping experience.

\section{FINDINGS}

An initial concern was whether shoppers entering the store would notice the Magic Mirror app embedded in the makeup counter alongside the other make-up products. It seemed many people did not notice it at first or were not drawn by the brand logo and strapline "What's your colour?" appearing on the tablets. We also observed that those shoppers who did stop and look at the display did not subsequently interact with it. As the stand-alone approach did not work, the shop assistants tried to entice passers-by to try out the app by telling them about what the virtual make-up app did and how easy it was to try. When someone began to use it, other passers-by then looked on with interest. But often they, too, needed to be encouraged by the shop assistant to try it. The few times when visitors used the app spontaneously without the encouragement of the shop assistant was when they saw other people who were using it, laughing or expressing admiration, interest or satisfaction. This occurred just a few times a day. The majority of the passers-by who the shop assistants approached, however, were willing and curious to test it. The passers-by either observed the interaction, waited for a turn to try it out on their own or simply walked over to the other tablet and tried that one.

As expected, the majority of people who interacted with the app were female. More surprisingly, 33\% of the men who were accompanying their partner or friends also tried it as well as five children, aged between 5 and 15, who were with their parents. Most of the visitors spent between 1 and 5 minutes using it with only around $10 \%$ of the visitors spending more than 5 minutes and less than 5\% under a minute. On average, women used the application longer than the men did.

The level of interest from the shoppers who tried the application was very high especially once they realized what features the application offered. One third of the visitors said they experimented with trying on different kinds of colours that they would not have otherwise and some actually went on to buy the product. It appeared that they found the app a convincing tool for trying make-up, seeing if it suited them and searching for the products they liked.

\section{Interactions with the Magic Mirror}

Data from using the app features during the three months period were analysed in terms of duration using the app per visitor and different looks/products tried on. When in the virtual try-on mode (where the virtual colors of the different make-ups could be changed at the bottom of the image), a user spent on average 2 minutes without switching to another page. The average number of tried-on products and looks per visitor was 18. According to the shoppers, that represents a much larger number of trials in comparison to the trials of real make-up testers. This data indicate that users spent considerable time looking at themselves with the virtual make-up and experimenting with different looks. Next, we examine in more detail the way they approached and used the Magic Mirror make-up app in terms of the shopper experience.

\section{Shopper experience}

Approximately $90 \%$ of the visitors were not sure what to expect or what to do with the make-up app, so the shop assistant told them to step closer, to touch the screen and then select the product category or a color. They also showed them how to use the app, which types of make-up it had and how to try on the different kinds. Many asked questions about the technology and about the features on the application. In general the visitors had no problems using the interface.

Initial surprise When the augmented make-up first appeared on a person's face, the majority (around 80\%) showed surprise through their facial expressions, which turned into delight when seeing, for example, a virtual lipstick appearing on their lips or eye shadow on their eyelids - exactly where it should be placed. More than $50 \%$ gasped or started laughing or smiling at themselves or their partners/friends/children. More than $70 \%$ exclaimed how amazing or cool it was and how much fun it was to use. Only one person said that she did not enjoy the experience. She also had negative remarks about all other technologies or products of the store. 10 people commented that they had seen similar technology beforehand, but most added that this form of augmentation appeared to be far more accurate and realistic than what they had tried before.

Convincing and realistic In most cases, it was found that the 2D tracking worked well: the virtual make-up appeared on the reflected face instantly, without delays, and persistently followed the person's movements. Around 75\% of the shoppers who tried it mentioned that it was convincing. It did look like the make-up was actually on their face as it was being mirrored back to them, and not superimposed on their reflection. For example, some were impressed how the shape of the lipstick adapted when they pouted their lips. However, for some who had thin lips, the alignment was not quite right. Nevertheless, the extent to which this 'off-tracking' affected their interaction added to 

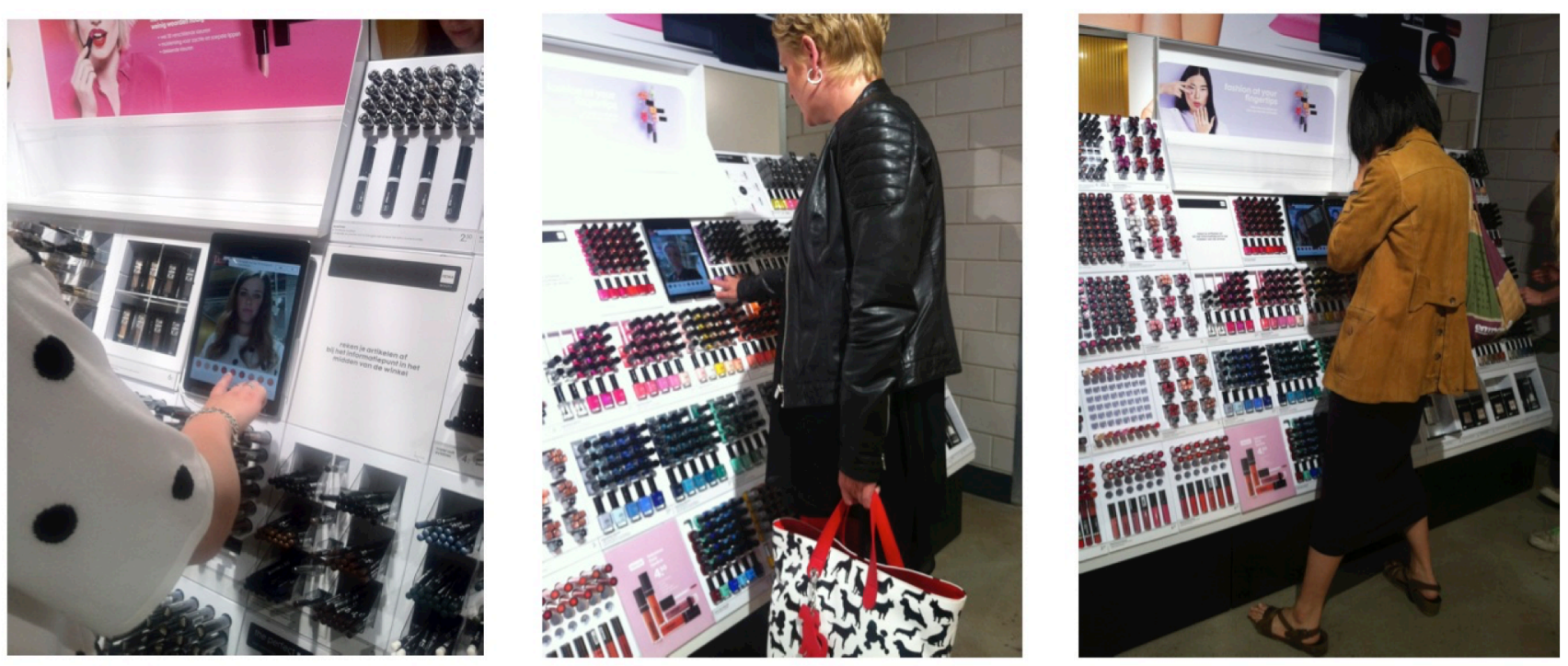

Figure 3: Female visitors trying on virtual make-up using the Magic Mirror application in the store

the experience rather than detracting from it. Occasionally, if someone moved their head too quickly, the tracking of the eyes or lips did not keep up, resulting in the eye shadow or lipstick appearing slightly off or left where it had previously been on the display. None of the shoppers perceived this misalignment to be annoying or disruptive, but rather had fun with observing what the application would do. $10 \%$ of visitors even tried to "trick" it by making sudden movements or grimaces with their face and then seemed pleased that they had fooled the application.

Between $75 \%-80 \%$ of shoppers were making facial expressions similar to the ones they did when wearing real make-up: pressing lips together, forming them in a shape of a kiss or lifting eyelids to see the color better. The way the make-up stuck to their eyelids and lips and moved with them as they made these changes to their facial features was what was considered most striking.

More than half of the women asked the shop assistant how similar or how different the virtual color was compared to the color of the real product. They wanted to know what the level of accuracy was compared to how the real lipstick would look on their lips. The shop assistant explained that the virtual colors were a very close proxy to how a color would appear on their lips or skin but that there was always a possibility of slight variation according to their skin tone.

Enjoyment The extent to which users enjoyed trying on the make-up seemed to play a role in their continued use of the app. More than $70 \%$ expressed their satisfaction with superlative comments, such as "This is so cool!", "Wow, amazing", "Such a fun application" and "I really like it." One third said that they tried out colors that they would not have previously thought suited them, thus encouraging them to expand beyond their usual set of choices. When the researcher asked the women if they usually put the testers on their faces, almost all of them said they would not normally do that, mainly due to hygienic reasons. Lipstick or eye shadows would thus normally be tried on the skin of a hand, but not on the face, while the virtual try-on allowed them to see and experience a realistic representation of how a type of eye shadow would appear on their eyes or lipstick color on their lips really appear on their face.

Occasionally, two people wanted to look at the screen together. The tablet tracks only one face, however, and if two faces appear on the screen at the same time the tracking selects only one of them. This may appear confusing. However, groups or couples trying to use it at the same time mainly perceived it as humorous and responded with laughter when the make-up appeared on the person in the background instead of the one trying it on.

One shopper commented that she was disturbed by the large discrepancy between the images of the models that appeared on the posters on the walls and displays and how the make-up appeared on her own face.

Throughout the week, $33 \%$ of the shoppers asked whether the application was integrated with social media, as they wanted to share their photo with the virtual make-up with their social network. Because the option wasn't available, they took photos with their own phones in order to upload it to Facebook or Instagram.

Men and children Despite the make-up trial and purchase process being traditionally a female activity, the use of the app was not limited to women. The men who did try it on, however, had a quite different experience. Around $75 \%$ of them felt compelled to state at the beginning that they didn't use make-up or made a gesture that this is not for 

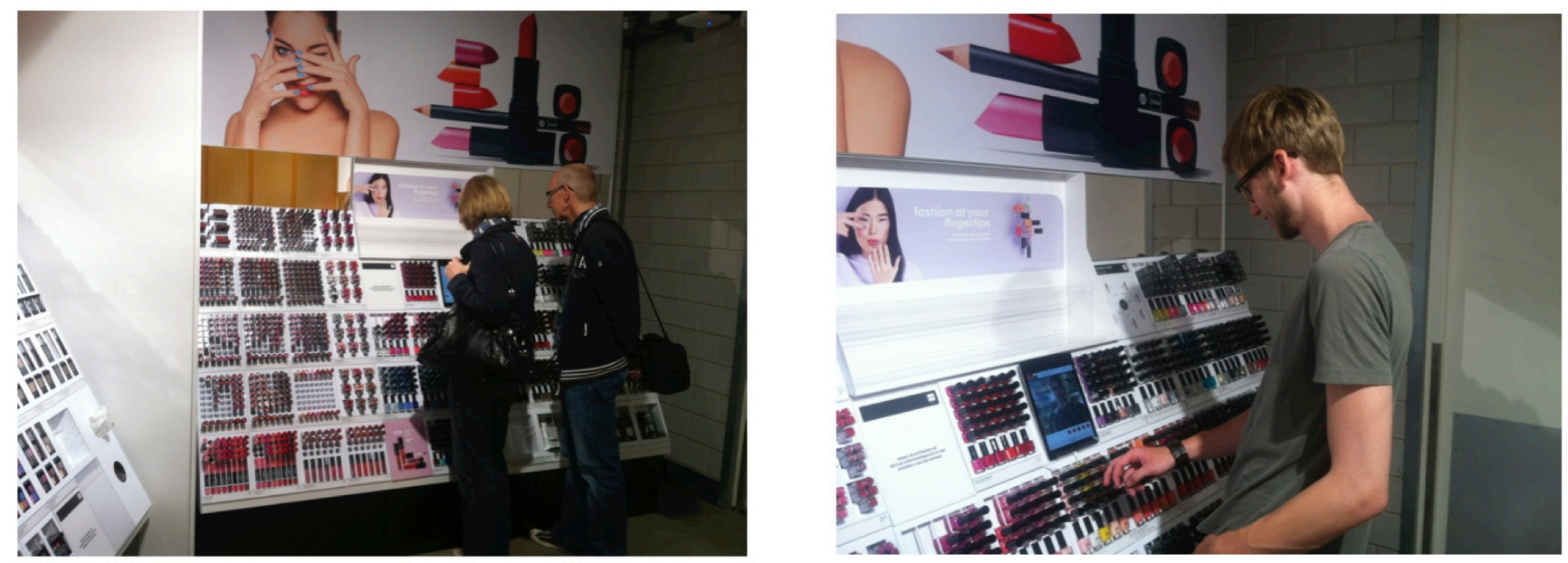

Figure 4: A couple using the application together (left) and a male visitor trying on virtual make-up (right)

them, but when the shop assistant remarked that many other men had already used it and that it was not real make-up, they became more open to the experience and more curious. In most cases they visibly enjoyed trying it on - the process being legitimized by their partners and the shop assistants. The more radical or dramatic the make-up looked on them, the more they laughed and the longer time they spent looking at themselves in the Magic Mirror app. They said that they would never try real make-up on but that the virtual one didn't seem so intimidating and didn't cause them to experience feelings of social embarrassment.

The few children who tried it on also showed a high level of curiosity and enjoyment. They laughed out loud and did not pay attention to anything else in the store - it appeared more like a playful app for them. They did not want to stop interacting with it until their parents (in most cases their mother) told them to stop as they were leaving.

While it was largely amusing for the men and children to use the app, it also provided a new set of circumstances for the women when they were shopping with their partners or children. Around $20 \%$ of the women commented that they felt less pressurized to finish browsing the make-up at the counter as it meant they were not keeping their family waiting. Hence, a side effect was to provide them with more time to browse the real make-up products.

Follow-up behavior During the observational study, 10 users of the make-up app then went on to buy the tried-on products. Three of them made a direct purchase of the products they had tried on without using a physical tester. Of the customers that made a purchase, 7 then subsequently tried out a color from the physical testers within that product category or color range. The presence of the shop assistant was important for follow-up behavior to occur. She was able to point out to customers where a particular product they had tried on using the app was physically located on the make-up counter.

\section{Survey results}

102 participants completed the online survey following interaction with the make-up app. 81 were female and 20 male (one person did not state their gender). 22 participants were between 18 and 24 years old, 16 between 25 and 34 years, 22 between 35 and 44 years and the remaining 42 participants were 45 or above.

Statements that were used in the scales were tested for reliability and validity in order to ensure that they could be used as appropriate measurement tools. We measured Cronbach's Alpha to see if it reached the required value of 0.7 and if the items correlated among themselves at a significance level $\mathrm{p}<0.05$. As perceived augmentation represents a rather novel concept, we conducted factor analysis to see if all items loaded on one component and if other related measures are satisfactory.

The reliability measure for perceived augmentation was suitable (Cronbach's Alpha $=0.797$ ) and all items correlated among themselves at the significance level $\mathrm{p}<0.05$. Factor and principal component analysis showed that all items loaded on one component and the extraction sum of squared loadings on the first component explained $56.73 \%$ of variance. Bartlett's test of sphericity was significant at $\mathrm{p}<0.01$ and $\mathrm{KMO}$ measure value was satisfactory at 0.788 which is above the required 0.7 . These evaluations showed that the items of perceived augmentation measured the same concept and could be used as an appropriate tool for the purpose of this analysis.

Furthermore, the playfulness scale had a Cronbach's Alpha of adequate value 0.843 and all constituent items were correlated at $\mathrm{p}<0.01$, confirming its reliability. When testing the convenience scale, it turned out that the Cronbach's Alpha was at an unsatisfactory level of 0.391 . Removing the third item, which seemed to be the most problematic, resulted in factor analysis showing that the remaining two items loaded on only one component whose Eigenvalue was 
above 1 and the sum of squared loadings explained $61.72 \%$ of variance. Raw factor loadings were .657 and .707 for the two items, which is above the required 0.4 level. We thus took the two items as reliable indicators of convenience.

Based on this analysis, the survey items thus provided valid measurement tools to how the respondents rated the perceived augmentation, the playfulness, the convenience dimension and conclusion of the shopping experience. Overall, the results showed that shoppers thought the app realistically augmented their faces with virtual make-up in real time. They also evaluated the experience to be very playful and a large majority indicated intentions of future engagement, such as subsequent use and talking to others about the application.

40

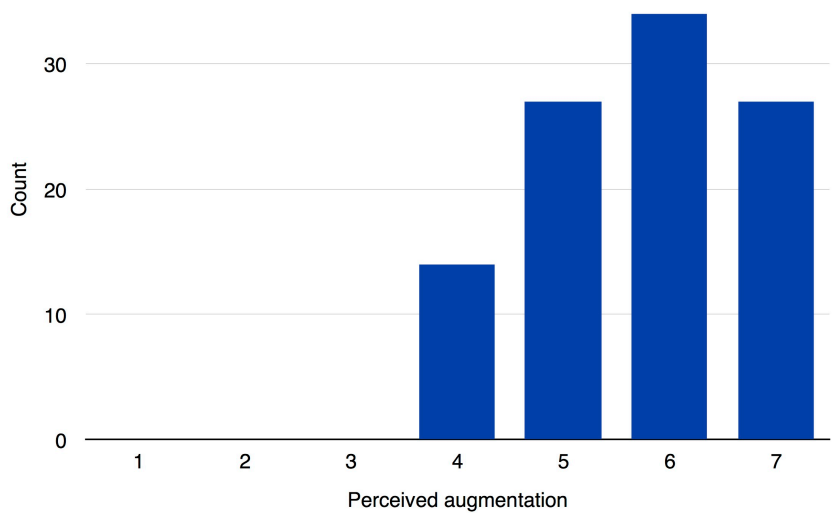

Figure 5: Histogram of frequencies showing how much the shoppers perceived the application to augment their faces (1 - do not agree at all, 7 - completely agree)

The reported values of perceived augmentation were the following. The minimum reported value on a scale from 1 to 7 (7 indicating the complete agreement that the Magic Mirror augment the faces with make-up in real-time) was 4 (which reflected neutrality in terms of agreement) and the maximum value was 7 . Value 7 , indicating a complete agreement, was also the most frequently occurring value (mode), 5.7 (with SD =.975) was the average level of agreement and 5.8 was a median value. The histogram shows the high levels of agreement with the statements about perceived augmentation (See Figure 5).

Furthermore, participants reported high values of playfulness (See Figure 6). The average level of agreement was 5.95 ( $\mathrm{SD}=.868)$, while mode was 7 and median value was 6. A more detailed analysis of the playfulness showed that participants reported application to be fun (mean $=6.30$ $(\mathrm{SD}=.888)$, median $=7$, mode $=7)$ and enjoyable (mean $=6.10$ $(\mathrm{SD}=1)$, median $=6$, mode $=7)$ and that it made them curious $($ mean=6.31 $(\mathrm{SD}=.995)$, median=7, mode=7). They also agreed that the application led them to exploration $($ mean=5.68 $(\mathrm{SD}=1.33)$, median=6, mode $=6)$ and to be more creative $($ mean $=5.55(\mathrm{SD}=1.38)$, median $=6$, ode $=7)$.
The playfulness of the experience thus related both to the enjoyment as well as to the creativity and exploration.

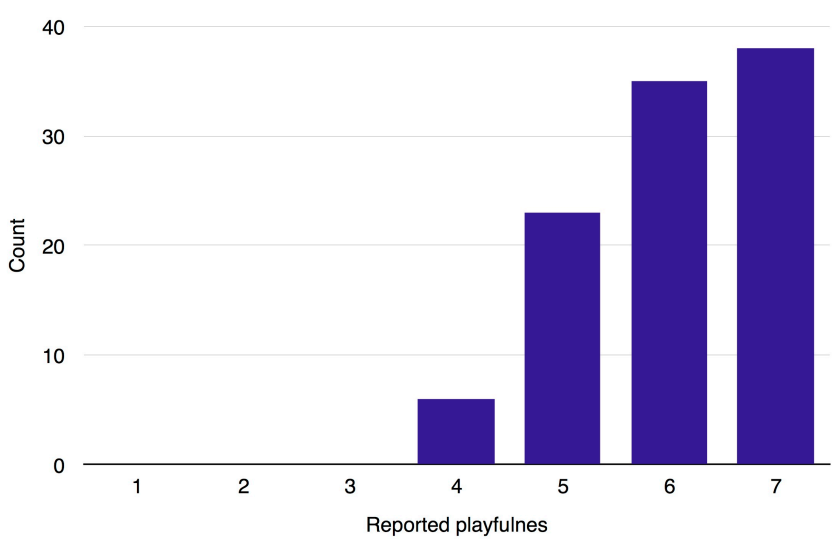

Figure 6: Histogram of frequencies showing how much the shoppers perceived the application to be playful (1 - do not agree at all, 7 - completely agree)

Reported values for convenience (See Figure 7) showed that respondents saw that the application allowed them to try on more colors than they would have otherwise been able to and that they felt less pressure to buy the products they had tried; the mean value of the agreement was 5.73 $(\mathrm{SD}=1.13)$, mode was 7 and median value 6 .

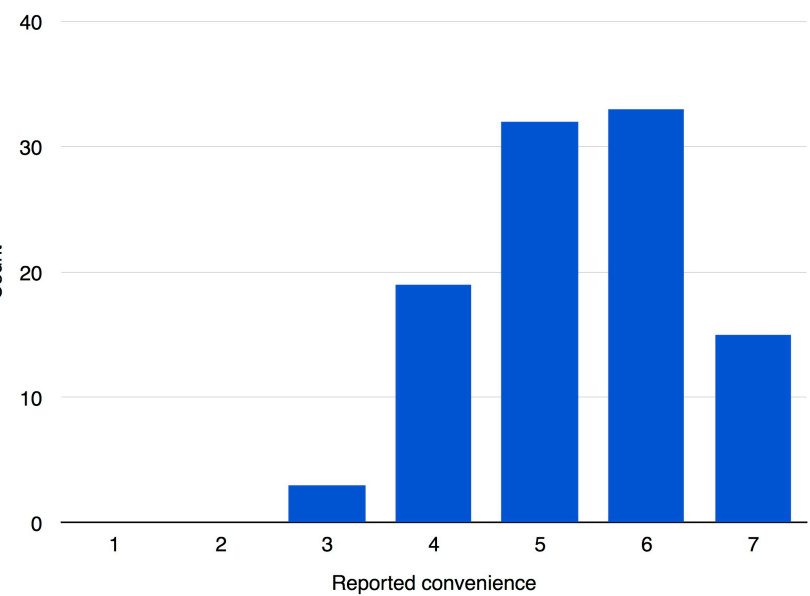

Figure 7: Histogram of frequencies showing how much the shoppers perceived the application to be convenient (1 - do not agree at all, 7 - completely agree)

The data collected about the shoppers' behavioral intentions were indicative of their intentions to use the application again $($ mean=5.82 $(\mathrm{SD}=1.22), \quad$ median $=6$, mode $=7)$, to spread word-of-mouth about it (mean=6.12 $(\mathrm{SD}=1.05)$, median $=6, \operatorname{mode}=7$ ) and to purchase items that they had tried $($ mean $=4.85(\mathrm{SD}=1.63)$, median $=5$, mode $=4)$. Figure 8 shows that they had the strongest intentions when it came to spreading word-of-mouth (WOM) about the app and that they also reported high intention to use it again. 


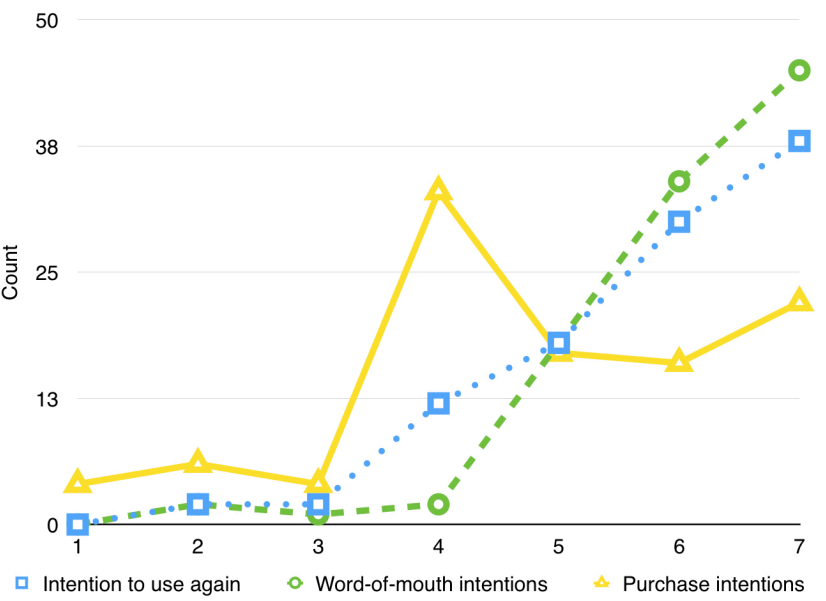

Figure 8: Histogram of frequencies for intentions to: reuse the application in the future; spread WOM (word-of-mouth) and purchase the tried-on make-up (1 - not at all, 7 - very much)

\section{Regression analysis}

We conducted a simple regression analysis to predict the following relations: the extent to which perceived augmentation predicts playfulness during application use and the convenience of it, as well as the correlations with behavioral intention. This type of analysis shows to which extent dimensions of experience are connected to each other and how much one dimension (e.g. playfulness) predicts another (e.g. behavioral intention to use the application again). The results are shown in Tables 2 and 3.

\begin{tabular}{l|l|l|l} 
& $\begin{array}{l}\mathbf{F}(\mathbf{1}, 100) \\
\text { (p value) }\end{array}$ & $\begin{array}{l}\mathbf{R} \\
\text { square }\end{array}$ & $\begin{array}{l}\text { Unstand. } \\
\text { Coefficient (SE) }\end{array}$ \\
\hline $\begin{array}{l}\text { Perc. Augm }=> \\
\text { Playfulness }\end{array}$ & $41,596(\mathrm{p}=.00)$ & .294 & $.482(\mathrm{SE}=.075)$ \\
$\begin{array}{l}\text { Return intention } \\
\text { WOM intention }\end{array}$ & $51,535(\mathrm{p}=.00)$ & .340 & $.731(\mathrm{SE}=.102)$ \\
\hline $\begin{array}{l}\text { Playfulness }=> \\
\text { Return intention }\end{array}$ & $77,263(\mathrm{p}=.00)$ & .289 & $.577(\mathrm{SE}=.090)$ \\
WOM intention & $32,792(\mathrm{p}=.00)$ & .436 & $.930(\mathrm{SE}=.106)$ \\
\end{tabular}

Table 2: Results of regression analysis with perceived augmentation and playfulness as predictors

From the first analysis (Table 2) we can observe that perceived augmentation acts a strong predictor of the playful experience that shoppers have with the application. Furthermore, both perceived augmentation and playfulness strongly correlate with visitors' intention to return to the application for further use and to talk about it to others.

With regard to the convenience and also purchase intentions, the values have lower predicting power, but are still significant. When respondents perceive the Magic Mirror to augment their faces, they also perceive the shopping experience to be more convenient, as the app allows them to try on more products than usual and they feel less pressured to purchase them. Both playfulness and perceived augmentation are relatively strong predictors of purchase intentions. Furthermore, convenience strongly correlates with intentions to return back for future use. It also associates significantly with intentions to tell others about the application or to purchase the tried items, however the associating power is weak, given the low values of both $\mathrm{R}$ square and coefficients.

\begin{tabular}{|c|c|c|c|}
\hline & $\begin{array}{l}F(1,100) \\
\text { (p value) }\end{array}$ & $\begin{array}{l}\mathbf{R} \\
\text { square }\end{array}$ & $\begin{array}{l}\text { Unstand. } \\
\text { coeff. (SE) }\end{array}$ \\
\hline Perc. Augm $=>$ & & & \\
\hline Convenience & $10,143(\mathrm{p}<.05)$ & .092 & $.352(\mathrm{SE}=.110)$ \\
\hline Purch. intention & $12,888(\mathrm{p}<.01)$ & .114 & $.565(\mathrm{SE}=.158)$ \\
\hline Playfulness $=>$ & & & \\
\hline Purch. intention & $15,917(\mathrm{p}=.00)$ & .137 & $.697(\mathrm{SE}=.175)$ \\
\hline Convenience $=>$ & & & \\
\hline Return intention & $26,426(\mathrm{p}=.00)$ & .209 & $.495(\mathrm{SE}=.096)$ \\
\hline WOM intention & $4,851(\mathrm{p}<.05)$ & .046 & $.199(\mathrm{SE}=.090)$ \\
\hline Purch. intention & $4,239(\mathrm{p}<.05)$ & .041 & $.291(\mathrm{SE}=.141)$ \\
\hline
\end{tabular}

Table 3: Results of regression analysis for convenience, purchase and return intention

These results demonstrate that as the level of perceived augmentation increases, so too does the user's playfulness with the app and subsequently the likelihood that they will use it again, talk about it with others or purchase the triedon products. The increased levels of perceived augmentation are associated also with perceived convenience, which further implies future behavior, but to a lesser extent in comparison to the playfulness.

\section{DISCUSSION}

The observations, the tracked data and the survey data all indicate that the shopper experience with the Magic Mirror make-up app was engaging, often leading people to more experimentation with different colors for the make-up products. It also helped some with decision-making when choosing or purchasing products. However, because of the unexpectedness and novelty of the app, many passers-by did not notice it initially or appeared wary of trying it on in public. This suggests that simply placing a tablet with such an AR app in a store will not lead to people trying it by themselves. Moreover, when placed in a store (rather than being an app a user downloads on his own device) that implies it requires someone in authority (i.e. a shop assistant) to legitimize a person using it in the store. Having a shop assistant to explain the app can make the shoppers feel at ease with trying it out themselves. Also, seeing others using it can draw people closer and encourage them to take part. The role of the "honeypot effect" [4] is, therefore, even more critical for this kind of novel technology. Especially when in an already visually busy or cluttered space, seeing others engaging with a virtual mirror can encourage passers-by to have a go as well.

Once given the go-ahead, shoppers were happy to experiment and use it in the way intended. Even men and children - to whom the app is not targeted at - found it compelling. Hence, far from being perceived as a gimmick, our observations showed that the people who tried the app perceived it to be convincing and useful. This was confirmed in the survey by the high scores for perceived 
augmentation. Based on this data, it can be stated that the enhancement of the face through the Magic Mirror AR technology seems to create a strong perception amongst shoppers that the digital and physical elements are aligned and that the face is directly augmented with the virtual elements. The shoppers also said that the difference between seeing a real lipstick and a virtual one on their lips using the Magic Mirror app was small; it felt as if the virtual make-up applied to their face that was looking back at them was actually real. Some shoppers even tried rubbing their eyelids to smudge the virtual eye shadow.

Our analysis also showed that shoppers experienced high levels of playfulness, excitement and surprise when interacting with the app. In some ways it is akin to McCarthy et al.'s [22] notion of enchantment, where the technology leads to a high level of absorption related to a state of concentration and attention.

For some of the shoppers, the app offered a different way of purchasing make-up. Firstly, such an app included playfulness in the activity of make-up purchase. Secondly, the virtual try-on allowed the potential customers to try on more products or colors because they could achieve this with a simple tap that takes considerably less time than trying on real products. The convenience allowed trying out colors that they would not otherwise have considered and thus permitted them to go beyond their usual set of choices. Thirdly, such an app has the potential to change the way make-up is bought as colors can be placed on the face more realistically, while usual make-up testing consists mainly of putting testers on the hand and not on the face.

Most of the users did not show or report any negative reactions and it would be interesting for future research to investigate the implications of disliking a virtual make-up on one's face. Would the perceived realism make them more averse to a brand than if they had tried the real makeup on their hand? Also, further research is needed to determine if people will use the app again once they are familiar with it and if new offers and novel product ranges can encourage such continuous use.

Moreover, in the current application, the make-up appears all at once on a user's face. While technically more demanding, it would be interesting to see the effect of make-up being applied gradually, as if someone really is putting it on their face, mimicking not only the end result, but the process as well. Such interactivity could then be used in a tutorial app for different types of looks. In terms of screen size, a tablet screen size actually offers an advantage, because fewer people appear in the camera view, thus making it less likely for the tracking to get confused and apply make-up to a person in a background. Also, switching between AR mode and an app with products menu appeared problematic for some people. An alternative would be to keep the AR mode on all the time and allow the shopper to do everything (product selection, colour changing) in the same mode.
This kind of Magic Mirror AR has much potential for other apps and settings, such as theatre, cinema, museums and art galleries, where dramatic, cinematic or historical looks could be experimented with. Further advances in using this kind of AR technology could provide a suite of tools for film and theatre artists, allowing them to try out looks without using expensive materials. Such a Magic Mirror could augment a visitor in an opera house, museum or other historic/cultural context, so they can appear with a wig, artistic make-up or clothes in the guise of a persona from the depicted period or context. With such tools, the experience could be expanded and lived more vividly. However, further research would need to be carried out to determine the extent to which people will suspend their disbelief in these other contexts.

In the context of health, enhancement with AR technology could show a predicted future image of the user, displaying potential changes that could occur due to healthy or unhealthy lifestyle choices. Similarly, virtual try-on could show potential outcomes of plastic or dental surgeries to patients. It could also be used in educational and training settings, providing make-up artists with a new tool to use when testing out their skills or perfecting new looks. It could introduce visitors to the art and design of make-up by giving them a chance to try to create the look of celebrities. There is much scope for introducing a new level of realism and engagement into virtual try-ons. With new advances in 3D motion capture, it may also be possible to model the whole body, opening up opportunities for adding other features, such as tails, ears and hair.

\section{CONCLUSION}

The findings from our in-situ study show much promise for future use of AR Magic Mirror apps that enable people to try on a virtual product. The technology is capable of creating an enchanting experience, whose multi-faceted character comprises usefulness, realism, playfulness and an element of surprise. However, in order for it to be successfully deployed, seamless integration of the app as part of the shopping journey is crucial. This requires the shop assistant to understand how to bring shoppers to the app and how to encourage them to use it. It also necessitates that the app be simple enough to use and the effect - while it need not be perfectly aligned - be convincing enough to evoke the fascination. While this study shows the positive reactions of shoppers to the app and builds on previous research about experience of virtual try-ons, future research can investigate how deployment and use of Magic Mirror changes outside a store or when shoppers become familiar with it as well as the value it can create in other domains.

\section{ACKNOWLEDGMENTS}

The authors would like to thank Holition Ltd for their support of this project, as well as to Morgan Harvey and Jo Iacovides for their help with the manuscript. This research was supported by the Swiss National Science Foundation grant P1TIP1_158595. 


\section{REFERENCES}

1. Dhiraj Amin and Sharvari Govilkar. 2015. Comparative Study of Augmented Reality SDK's. International Journal on Computational Science \& Applications 5, 1: 11-26. http://doi.org/10.5121/ijcsa.2015.5102

2. Ronald Azuma, Reinhold Behringer, Simon Julier, and Blair Macintyre. 2001. Recent Advances in Augmented Reality. IEEE Computer Graphics and Applications 21, 6: 34-47.

3. Mark Billinghurst and Hirokazu Kato. 2002.

Collaborative augmented reality. Communications of the ACM 45, 7: 64-70.

http://doi.org/10.1145/514236.514265

4. H Brignull and Y Rogers. 2003. Enticing people to interact with large public displays in public spaces. Proceedings of INTERACT (Vol. 3), 17-24. http://doi.org/10.1.1.129.603

5. Giuseppe Caggianese, Pietro Neroni, and Luigi Gallo. 2014. Natural Interaction and Wearable Augmented Reality for the Enjoyment of the Cultural Heritage in Outdoor Conditions. In Augmented and Virtual Reality. Springer International Publishing, 267-282. http://doi.org/10.1061/40339(206)47

6. Julie Carmigniani, Borko Furht, Marco Anisetti, Paolo Ceravolo, Ernesto Damiani, and Misa Ivkovic. 2011. Augmented reality technologies, systems and applications. Multimedia Tools and Applications 51: 341-377. http://doi.org/10.1007/s11042-010-0660-6

7. Kuo En Chang, Chia Tzu Chang, Huei Tse Hou, Yao Ting Sung, Huei Lin Chao, and Cheng Ming Lee. 2014. Development and behavioral pattern analysis of a mobile guide system with augmented reality for painting appreciation instruction in an art museum. Computers and Education 71: 185-197.

http://doi.org/10.1016/j.compedu.2013.09.022

8. Kun-Hung Cheng and Chin-Chung Tsai. 2013. Affordances of Augmented Reality in Science Learning: Suggestions for Future Research. Journal of Science Education and Technology 22: 449-462. http://doi.org/10.1007/s 10956-012-9405-9

9. Hyejeung Cho and Norbert Schwarz. 2012. I Like Your Product When I Like My Photo: Misattribution Using Interactive Virtual Mirrors. Journal of Interactive Marketing 26, 4: 235-243. http://doi.org/10.1016/j.intmar.2012.03.003

10. Francesca De Crescenzio, Massimiliano Fantini, Franco
Persiani, Luigi Di Stefano, Pietro Azzari, and Samuele Salti. 2011. Augmented reality for aircraft maintenance training and operations support. IEEE Computer Graphics and Applications 31, 1: 96-101. http://doi.org/10.1109/MCG.2011.4

11. Elizabeth FitzGerald, Rebecca Ferguson, Anne Adams, Mark Gaved, Yishay Mor, and Rhodri Thomas. 2013. Augmented reality and mobile learning: the state of the art. International Journal of Mobile and Blended Learning 5, 4: 43-58. http://doi.org/10.4018/ijmbl.2013100103

12. Sandra Forsythe, Chuanlan Liu, David Shannon, and Liu Chun Gardner. 2006. Development of a scale to measure the perceived benefits and risks of online shopping. Journal of Interactive Marketing 20, 2: 5575. http://doi.org/10.1002/dir.20061

13. Tseng-Lung Huang and Feng Hsu Liu. 2014. Formation of augmented-reality interactive technology's persuasive effects from the perspective of experiential value. Internet Research 24, 1: 82-109. http://doi.org/10.1108/IntR-07-2012-0133

14. Tseng-Lung Huang and Shuling Liao. 2015. A model of acceptance of augmented-reality interactive technology: the moderating role of cognitive innovativeness. Electronic Commerce Research 15, 2: 269-295. http://doi.org/10.1007/s10660-014-9163-2

15. Ana Javornik. 2014. Classifications of Augmented Reality Uses in Marketing. IEEE International Symposium on Mixed and Augmented Realities 2014.

16. Ana Javornik. 2015. "Wow, I can augment myself?" Measuring effects of perceived augmentation and interactivity on affective, cognitive and behavioral consumer responses. 2015 Academy of Marketing Conference - The Magic in Marketing.

17. Jiyeon Kim and Sandra Forsythe. 2008. Adoption of virtual try-on technology for online apparel shopping. Journal of Interactive Marketing 22, 2: 45-59. http://doi.org/10.1002/dir.20113

18. Panos Kourouthanassis, Costas Boletsis, Cleopatra Bardaki, and Dimitra Chasanidou. 2015. Tourists responses to mobile augmented reality travel guides: The role of emotions on adoption behavior. Pervasive and Mobile Computing 18: 71-87. http://doi.org/10.1016/j.pmcj.2014.08.009

19. D W F Van Krevelen and R Poelman. 2010. A Survey of Augmented Reality Technologies , Applications and 
Limitations. The International Journal of Virtual Reality 9, 2: 1-20.

20. Tobias Langlotz, Stefan Mooslechner, Stefanie Zollmann, Claus Degendorfer, Gerhard Reitmayr, and Dieter Schmalstieg. 2012. Sketching up the world: Insitu authoring for mobile Augmented Reality. Personal and ubiquitous computing 16, 6: 623-630.

http://doi.org/10.1007/s00779-011-0430-0

21. Luoqi Liu, Hui Xu, Junliang Xing, Si Liu, Xi Zhou, andShuicheng Yan. 2013. "Wow! you are so beautiful today!" Proceedings of the 21st ACM international conference on Multimedia - MM'13: 3-12. http://doi.org/10.1145/2502081.2502126

22. John Mccarthy, Peter Wright, Jayne Wallace, and Andy Dearden. 2006. The experience of enchantment in human - computer interaction. Personal and ubiquitous computing 10, 6: 369-378.

http://doi.org/10.1007/s00779-005-0055-2

23. Aurélie Merle, Sylvain Senecal, and Anik St-Onge. 2012. Whether and How Virtual Try-On Influences Consumer Responses to an Apparel Web Site. International Journal of Electronic Commerce 16, 3: 41-64. http://doi.org/10.2753/JEC1086-4415160302

24. Ji-won Moon and Young-gul Kim. 2001. Extending the TAM for a World-Wide-Web context. Information \& Management 38: 217-230.

25. Guda van Noort, Hilde a.M. Voorveld, and Eva a. van Reijmersdal. 2012. Interactivity in Brand Web Sites: Cognitive, Affective, and Behavioral Responses Explained by Consumers' Online Flow Experience. Journal of Interactive Marketing 26, 4: 223-234. http://doi.org/10.1016/j.intmar.2011.11.002

26. Thomas Olsson, Else Lagerstam, Tuula Kärkkäinen, and Kaisa Väänänen-Vainio-Mattila. 2013. Expected user experience of mobile augmented reality services: A user study in the context of shopping centres. Personal and Ubiquitous Computing 17, 2: 287-304. http://doi.org/10.1007/s00779-011-0494-x

27. Jenny Preece, Helen Sharp, and Yvonne Rogers. 2015. Preece, Jenny, Helen Sharp, and Yvonne Rogers. Interaction Design-beyond human-computer interaction. John Wiley \& Sons.

28. Philipp A. Rauschnabel, Alexander Brem, and Bjoern S. Ivens. 2015. Who will buy smart glasses? Empirical results of two pre-market-entry studies on the role of personality in individual awareness and intended adoption of Google Glass wearables. Computers in Human Behavior 49: 635-647.

http://doi.org/10.1016/j.chb.2015.03.003

29. Holger Schnädelbach, Boriana Koleva, Martin Flintham, et al. 2002. The Augurscope : A Mixed Reality Interface for Outdoors. Proceedings of the SIGCHI conference on Human factors in computing systems: Changing our world, changing ourselves, 4: 916. http://doi.org/10.1145/503376.503379

30. Marcus Specht, Stefaan Ternier, and Wolfgang Greller. 2011. Dimensions of Mobile Augmented Reality for Learning: A First Inventory. Journal of the Research Center for Educational Technology 7, 1: 117-127.

31.Z Yovcheva, Dimitrios Buhalis, and C Gatzidis. 2012. Smartphone Augmented Reality Applications for Tourism. e-Review of Tourism Research 10, 2: 63-66. Retrieved from http:/eprints.bournemouth.ac.uk/20219/4/licence.txt

32. Feng Zhou, Henry Been-Lirn Duh, and Mark Billinghurst. 2008. Trends in augmented reality tracking, interaction and display: A review of ten years of ISMAR. 2008 7th IEEE/ACM International Symposium on Mixed and Augmented Reality: 193-202. http://doi.org/10.1109/ISMAR.2008.4637362 